\title{
Análise do uso e cobertura do solo dos promontórios costeiros do litoral centro-norte de Santa Catarina
}

\author{
Taciana Ziembowicz* \\ Rosemeri Carvalho Marenzi, Helia del Carmen Farías Espinoza**
}

\section{Resumo}

Os promontórios costeiros no litoral centro-norte catarinense estão isolados pela urbanização e mar, estes tem grande relevância na conservação da biodiversidade, por serem remanescentes do Bioma Mata Atlântica. Por isso, objetivou-se analisar o uso e cobertura do solo nos promontórios costeiros de Penha, Itajaí e Balneário Camboriú. Neste artigo foram georeferenciadas e geoprocessadas as imagens de satélite no SPRING 5.1.5, juntamente com as saídas de campo para validação dos dados. Resultou em mapas temáticos com as informações da configuração da paisagem desses promontórios costeiros. Foi possível perceber a ausência de Floresta Ombrófila Densa Clímax em dois promontórios, em Balneário Camboriú e Itajaí, isto se deve as diferentes ocupações que ocorreram ao longo da história dos municípios. Além disso, pode-se concluir que a perpetuidade da biodiversidade é prejudicada pela fragmentação entre os três promontórios pela ausência de corredores e a presença de urbanização, tais como a BR-101, Interpraias e conurbação urbana.

Palavras-chave: Paisagem; Promontórios Costeiros; Fragmentação.

\footnotetext{
Fundação Municipal do Meio Ambiente de Brusque (taciana1984@hotmail.com).

** Universidade do Vale do Itajaí (helia@univali.br).
}

Geosul, Florianópolis, v. 29, n. 57, p 43-64, jan./jun. 2014 
ZIEMBOWICZ, T. et al. Análise do uso e cobertura do solo dos ...

Analysis of land use and cover of the coastal promontories of central coast north of Santa Catarina

\begin{abstract}
The coastal promontories in the north-central coast of Santa Catarina are isolated by urbanization and sea, these have great importance in conservation of biodiversity because they are remnants of Atlantic Forest biome. Therefore, the objective was to examine the use and land cover in the coastal promontories of Penha, Itajai and Balneário Camboriú. This article has its images georeferenced in SPRING 5.1.5, together with field trips to confirm the data. It resulted in thematic maps with information on the configuration of the landscape of coastal promontories. It was possible to notice the abscense of Edge Florest in two promontories of Balneário Camboriú and Itajaí, this is due to the differents occupations that have occured throughout the history of the cities. Moreover, it can be concluded that the perpetuity of biodiversity is impaired by fragmentation between the three promontories by the absence of corridors and the presence of urbanization, such as BR101, Interpraias and urban conurbation.
\end{abstract}

Key words: Landscape; Coastal Promontory; Fragmentation.

\title{
Introdução
}

A crescente urbanização dos ambientes naturais tem resultado em degradação dos últimos remanescentes de Floresta Ombrófila Densa no Brasil, e perda da biodiversidade local - a expressiva diversidade biológica localizada no Bioma Mata Atlântica, rica em espécies endêmicas, a torna um dos hotspots de conservação do planeta Terra. Além disto, este bioma integra uma das maiores florestas tropicais das Américas, cobrindo cerca de 150 milhões de hectares, possuindo alta heterogeneidade de habitats - devido a variedade de altitudes - combinada com regiões de alta e baixa precipitação. Faz-se notável, portanto, a necessidade 
ZIEMBOWICZ, T. et al. Análise do uso e cobertura do solo dos ...

de estudos sobre como vem ocorrendo os impactos antrópicos e qual a resultante na configuração da paisagem alterada pela fragmentação (CHEDIACK, 2008; Ribeiro, 2009).

Além disso, a Mata Atlântica como floresta tropical ocupa um papel indispensável na prestação de serviços ambientais, tais como: regulação do clima, do ciclo hidrológico e de carbono; proteção das margens e calhas dos rios; provisão de bens diretos; suporte para a formação dos solos. Pode-se agregar ainda valores turísticos, culturais, esportivos, de lazer e estéticos (Lévêque, 1999; Gilbert, 2010; Bayon \& Jenkins 2010; Young et al,. 2010). No entanto, os ecossistemas fragmentados têm seus processos e ciclos perturbados, desiquilibrando os serviços prestados e implicando em efeitos interligados como, por exemplo, a perda da variabilidade genética pelo isolamento das populações (endogamia), a extinção local de espécies adaptadas para aquele hábitat e o aumento de espécies exóticas e comuns que demarcam ambientes alterados (LUZ, 2002; RICKLEFS, 2003).

A Mata Atlântica é a vegetação predominante nas zonas costeiras brasileiras - um ecossistema único integrado por manguezais, recifes de coral, restingas, lagunas, estuários e deltas, também amplos em diversidade biológica (DIEGUES, 2001; OLIVEIRA, 2010; SUHOGUSOFF \& PILIACKAS, 2007). Tais áreas - incluindo seus promontórios - são degradadas principalmente pela construção de novas moradias e complexos industriais, turísticos e comerciais, alocados de forma desordenada sobre as áreas naturais (SOARES et.al, 2006; OLIVEIRA, 2010).

Outra característica das zonas costeiras é a presença de promontórios, que são serras cristalinas litorâneas comumente compostas de granitos e gnaisses, com formato de pontas rochosas de diversos tamanhos (largura e comprimento), atingindo mares, oceanos, lagunas, estuários e baías (CERCHIARI, 1999; Horn Filho, 2011). Os promontórios fazem parte de um complexo maior chamados maciços costeiros, representados por áreas montanhosas com origem em massas magmáticas plutônicas ou metamórficas, sendo relativamente extensos. No estado de Santa Catarina, os 
ZIEMBOWICZ, T. et al. Análise do uso e cobertura do solo dos ...

promontórios que antes possuíam áreas de vegetação contíguas com as planícies litorâneas foram se tornando gradativamente fragmentos isolados de Mata Atlântica em diversos estágios de conservação (HORN FILHO, 2011).

A supressão de vegetação ocorrida nas zonas litorâneas deriva-se em manchas isoladas, que por sua vez exercem uma função ecológica debilitada e distinta do desempenho de uma floresta em continuidade. Após a degradação, inicia-se um processo natural de recomposição da área, com as plantas pioneiras que iniciam um processo de recolonização que confere uma menor diversidade de organismos na formação florestal. Entretanto, se houver a conectividade entre manchas de vegetação remanescentes pode sustentar a estabilidade no funcionamento dos ecossistemas (BOCCO et al., 2005; CADENASSO et.al, 2003; PICHANCOURT et al., 2006; RICKLEFS, 2003).

Li \& Mander (2009) advertem que o avanço das zonas urbanas sobre as áreas vulneráveis, a gestão inadequada dos recursos naturais e o despreparo para agir perante emergências podem resultar em calamidades públicas, trazendo altos custos econômicos e sociais (COSTANZA et al., 2006). Portanto, a partir do estudo dos maciços costeiros e dos promontórios rochosos, objetos deste estudo, aspira-se avaliar como ocorrem os usos, as formas da ocupação e a cobertura vegetal remanescente nestes locais, traçando um panorama sobre a conservação da biodiversidade.

\section{Metodologia}

A área de estudo situa-se no litoral centro-norte catarinense, classificado segundo Guadagnin \& Laidner (1999): Promontório da Praia Vermelha em Penha, Promontório da Costa Brava em Balneário Camboriú e Promontório de Cabeçudas em Itajaí.

Foi utilizado o Sistema de Processamento de Informações Georeferenciadas (SPRING 5.1.1) para a confecção dos mapas de uso e cobertura dos solos. Inicialmente, as imagens de satélite 
ZIEMBOWICZ, T. et al. Análise do uso e cobertura do solo dos ...

QuickBird, produto bruto com resolução de $2,4 \mathrm{~m}$, compostas por quatro canais multiespectrais (azul, verde, vermelho e infravermelho próximo) foram georreferenciadas através dos pontos obtidos em campo com o Global Positioning System (GPS) Trimble Juno com precisão de 2 a 5 m, além da utilização da linha de costa referente a $30 \mathrm{~m}$ do SPU.

Logo após, procedeu-se fazendo a segmentação, que consistiu em dividir a imagem em regiões pela similaridade dos pixels para obtenção de áreas homogêneas. Além disso, áreas que ficaram erroneamente definidas pela classificação do sistema, foram refeitas manualmente dentro da edição matricial. Posteriormente, foram feitas as classificações das tipologias vegetais de acordo com as observações em campo, tipo de textura e coloração definidas pela utilização dos canais $(4,3,1)$.

A classificação da vegetação seguiu os seguintes critérios: observação em campo e resposta espectral da imagem de satélite, sendo qualificadas como: Floresta Ombrófila Densa (FLOD) em estágio inicial, médio, avançado e clímax; Formação Pioneira com Influência Marinha (FPMI) ou restinga herbácea, arbustiva e arbórea; vegetação exótica (agrupamentos de Pinus sp. ou Eucalyptus sp.); Formação Pioneira com Influência Flúvio-Marinha (FPIFM) ou mangue e Campo (predomínio de gramíneas plantadas ou invasoras).

$\mathrm{O}$ reconhecimento na imagem dos diferentes estágios sucessionais da Floresta se deu por meio das diversas texturas, que aumentam de intensidade e de tonalidade com avanço/maturidade da vegetação. No campo este reconhecimento ocorreu pelos critérios fitofisionômicos estabelecidos pela Resolução Conama $n^{\circ}$ 04 e n²6 (BRASIL, 1994), n²61 (SANTA CATARINA, 1999) e Lei da Mata Atlântica (Brasil, 2006).

A definição das tipologias herbácea, arbustiva e arbórea da Formação Pioneira com Influência Marinha na imagem adveio da proximidade do mar e diferenciação textural. Já no campo, esta definição sucedeu-se por meio da visualização do hábito de crescimento dos agrupamentos dominantes. Concomitantemente, nomeou-se os usos como: urbanização, solo exposto, pedreira, e demais situações determinando em: praia, costeira/costão rochoso e corpo d'água/oceano. 
ZIEMBOWICZ, T. et al. Análise do uso e cobertura do solo dos ...

\section{Resultados e discussão}

\section{Promontório da Praia Vermelha}

O promontório da Praia Vermelha está localizado em Penha $\mathrm{SC}$, sendo que o município tem uma população de 25.141 habitantes, com uma área de $62.000 \mathrm{~km}^{2}$, densidade demográfica de $406 \mathrm{hab} / \mathrm{km}^{2}$. A economia é baseada no turismo, na maricultura e na pesca. A incidência de pobreza é de 33\% da população (IBGE, 2010).

De acordo com o mapa de uso e cobertura do solo (figura 1) obteve-se os dados representado na tabela 1 .

Tabela 1: Dados referentes ao mapeamento de uso e ocupação do solo da morraria da Praia Vermelha

\begin{tabular}{lcc}
\hline \multicolumn{1}{c}{ Tipologia } & Área (ha) & Proporção (\%) \\
\hline Praia & 20,57 & 1,04 \\
Costão Rochoso ou Costeira & 39,16 & 1,98 \\
Solo Exposto & 17,79 & 0,90 \\
Urbanização & 134,09 & 6,78 \\
Corpo d'água & 988,77 & 50,00 \\
Campo & 98,48 & 5,00 \\
Vegetação exótica & 2,82 & 0,14 \\
Restinga Herbácea & 14,38 & 0,73 \\
Restinga Arbustiva & 62,01 & 3,13 \\
Restinga Arbórea & 105,25 & 5,32 \\
Estágio Inicial & 23,92 & 1,21 \\
Estágio Médio & 121,89 & 6,16 \\
Estágio Avançado & 137,08 & 6,93 \\
Clímax & 211,40 & 10,69 \\
TOTAL & $1.977,61$ & 100,00 \\
\hline
\end{tabular}


ZIEMBOWICZ, T. et al. Análise do uso e cobertura do solo dos ...

Diante deste cenário identifica-se que a pressão sobre a zona costeira é ressaltada por processos erosivos referentes ao solo exposto ou de sedimentação, lotes edificados e não edificados, urbanização, alteração do ambiente natural pela disseminação de espécies exóticas visualizadas em campo.

A alteração da paisagem referente ao campo (98,48 ha) pode indicar edificações demolidas, abandono de área para pastagem ou cenário futuro de construção de moradias; e o processo de urbanização (134,09 ha) ocorre pressão direta de vias públicas e construções identificadas na área que vão degradando o ecossistema do promontório. Destaca-se, ainda, que a área urbana era de 55,51 ha, mas atualmente definiu-se com um valor de 134,09 ha, derivando uma triplicação no uso do solo nessa classe (MARENZI, 2004).

A paisagem neste promontório encontra-se parcialmente antropizada e fragmentada, porém com pelo menos um grande bloco de vegetação com conexões entre os diversos fragmentos, o que permite a dispersão das espécies e o fluxo gênico, entretanto com processos funcionais preservados.

Porém, o recorte das duas áreas diferencia-se e ainda o sistema de interpretação de cada pesquisador distingue-se, por isso esse valor é uma estimativa do cenário atual. De qualquer forma, a pressão antrópica sobre o promontório está causando modificações na distribuição das fitofisionomias e revelando uma redução nas áreas onde havia Floresta Ombrófila Densa clímax e em estágio avançado.

Apesar disso, verifica-se complexidade de estratos verticais e de heterogeneidade espacial, o que possibilita o estabelecimento de uma gama maior de espécies, devido a maior diversidade de hábitats e refúgios reforçando a amplitude de nichos ecológicos. A compreensão da heterogeneidade dos ambientes favorece, principalmente, a biota, pois a diversidade biológica deve perpetuar na natureza para que todos os processos naturais mantenham-se num ciclo dinâmico constante sadio para a vida (BARRETO, 1999; MACHADO et al, 2004; Li \& MANDER, 2009).

Diante disso, a fragmentação da vegetação em manchas menores e isoladas pela urbanização compromete a perpetuidade 
ZIEMBOWICZ, T. et al. Análise do uso e cobertura do solo dos ...

da biota e dos processos ecossistêmicos, podendo ao longo do tempo extinguir espécies localmente (SANTOS, 2003). Portanto, mesmo que haja diversos tipos de manchas (classes de uso e cobertura do solo) isto não sugere uma maior biodiversidade, esta situação não garante a distribuição das espécies representadas em população mínima viável (METZGER et al, 2009).

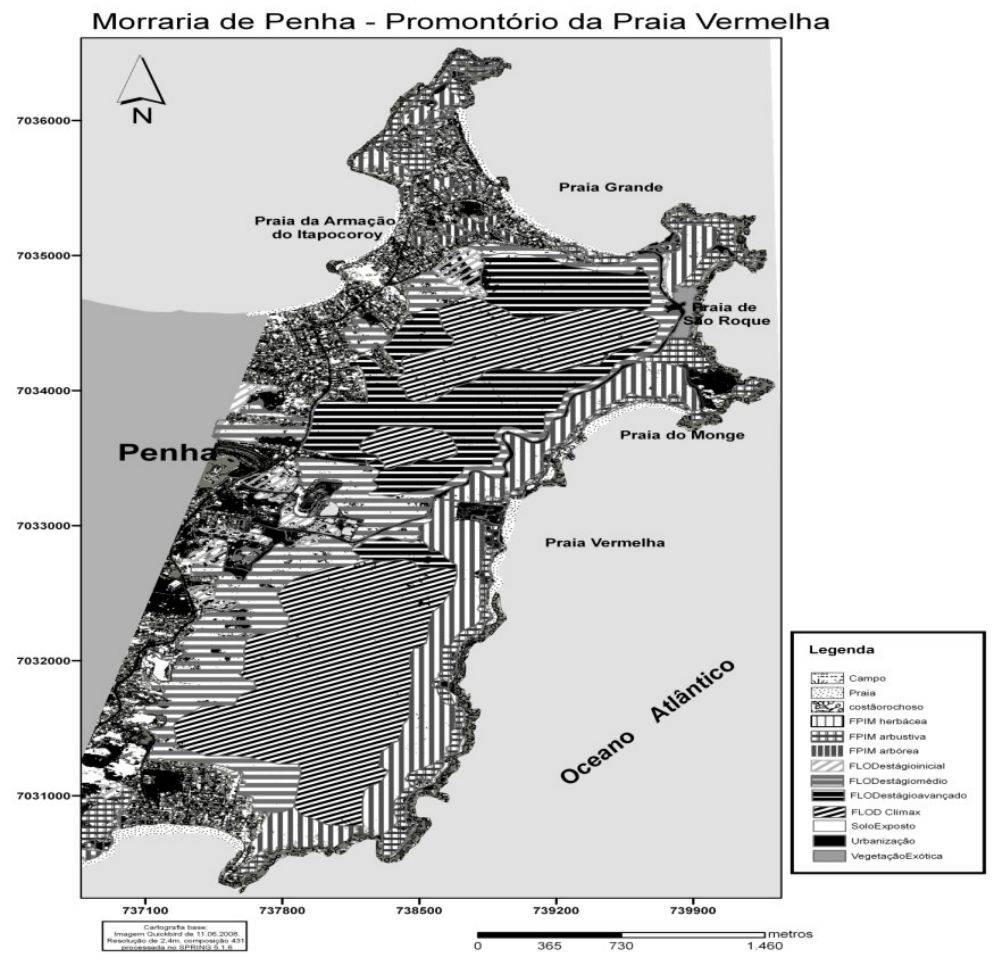

Figura 1: Mapa de uso e ocupação do solo do Promontório da Praia Vermelha em Penha - SC.

O Promontório da Praia Vermelha oferece uma infra-estrutura rudimentar para atender o turista e também o morador que desfruta da beleza natural do local. Confirmado pela ausência de transporte 
ZIEMBOWICZ, T. et al. Análise do uso e cobertura do solo dos ...

público e de pavimentação, todavia há abastecimento com água encanada, rede telefônica, coleta de lixo e a rede de esgoto são algumas das melhorias verificadas em campo (IFES, 2007).

\section{Promontório de Cabeçudas}

O promontório de Cabeçudas está localizado na cidade de Itajaí - SC, que apresenta uma população de 183.373 habitantes, com $289 \mathrm{~km}^{2}$, sendo $634 \mathrm{hab} / \mathrm{km}^{2}$. A economia é baseada na atividade portuária, mas com representativa pesca e turismo. $\mathrm{O}$ índice de pobreza está em 29\% da população (IBGE, 2010).

Através do mapa de uso e cobertura do solo (figura 2) foram reunidos os dados (tabela 2 ).

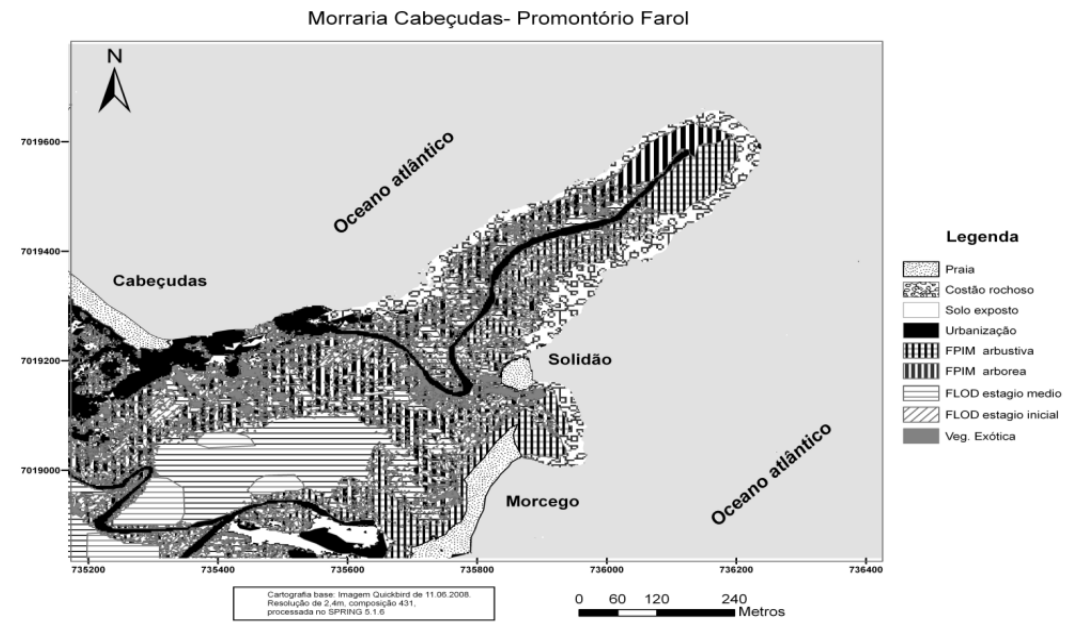

Figura 2: Mapa de uso e cobertura do solo do Promontório de Cabeçudas em Itajaí, SC. 
ZIEMBOWICZ, T. et al. Análise do uso e cobertura do solo dos ...

Tabela 2: Dados referentes ao levantamento de uso e cobertura do solo do Promontório de Cabeçudas - Itajaí, SC.

\begin{tabular}{lcc}
\hline \multicolumn{1}{c}{ Tipologia } & Área (ha) & Proporção (\%) \\
\hline Praia & 2,53 & 2,08 \\
Costão Rochoso ou Costeira & 4,44 & 3,66 \\
Urbanização & 8,08 & 6,66 \\
Corpo d'água & 65,89 & 54,37 \\
Vegetação exótica & 3,64 & 3,00 \\
Arbustiva & 7,96 & 6,57 \\
Arbórea & 9,10 & 7,51 \\
Inicial & 4,24 & 3,50 \\
Médio & 15,31 & 12,63 \\
TOTAL & 121,19 & 100 \\
\hline
\end{tabular}

Cabe destacar a existência de duas espécies da flora que formam dois núcleos com expressiva densidade: Hibiscus pernambucensis (algodeiro-da-praia), pertencente a família Malvaceae e Polistychum adiantiformes, pertencente a família Polypodiophyta (samambaia). Também, foi possível observar a presença de uma área reduzida na praia da Solidão de FPIM herbácea, resultante do nível da maré. $\mathrm{Na}$ imagem de satélite analisada não foi possível diferenciar esse núcleo e devido ao tamanho reduzido, foi apenas verificada em campo.

Há uma diferença entre as classificações adotadas neste trabalho se comparado com Ferreira (2009), sendo assim haveriam as variações entre as formações vegetacionais nos dois estudos. Cabe destacar, ainda, que uma porção da área possui edificações consolidadas na Praia de Cabeçudas, além do domínio da Marinha na parte que adentra o mar. Entretanto, as imagens de satélite utilizadas nos dois trabalhos são de datas diferentes, o primeiro autor utilizou uma IKONOS de 2001 e a seguinte uma QUICKBIRD de 2008, isso pode caracterizar uma intensificação na pressão negativa exercida pelo turismo sobre a área e um incremento nas áreas de vegetação exótica neste trabalho. 
ZIEMBOWICZ, T. et al. Análise do uso e cobertura do solo dos ...

É possível verificar que é predominante porção de FLOD em estágio médio e FPIM (restinga) arbórea e arbustiva. No entanto, é percebido um isolamento que ocorre com o Promontório de Cabeçudas devido ao cinturão de urbanização que advém da Praia Brava na porção sul e da Praia de Cabeçudas na porção norte. Isto denota um processo de fragmentação de habitats, configurando as manchas de vegetação em forma de ilhas isoladas. Metzger (2000) \& Metzger et al. (2009) corroboram afirmando, que a maioria dos remanescentes da Floresta Ombrófila Densa no estado de São Paulo existe em pequenos fragmentos com ausência de corredores e em estágio secundário no início ou médio de sucessão.

Da mesma forma, são identificadas manchas de vegetação exótica e mista sobre a vegetação original de Floresta e área de restinga, resultando em pressão e alteração da paisagem. Foram identificados indivíduos de Eucalyptus sp. de grande porte e iniciando um processo de envelhecimento, inclusive percebeu-se que a vegetação nativa desenvolve-se entre a vegetação exótica.

A introdução de espécies exóticas e a expansão da urbanização por novos empreendimentos e moradias, acarreta num aumento no número de manchas, isolamento e compromete a perpetuidade da fauna local. Considerando o habitat como o conjunto de manchas dentro da paisagem que o organismo usufrui, quando o tamanho dessa mancha diminui, reduz a área disponível e torna mais vulnerável as espécies frente à estocasticidade demográfica (HANSKI, 1998).

Neste promontório a uma heterogeneidade espacial menor se compara com o promontório da Praia Vermelha, é decorrente do estágio inicial e médio de FLOD com alterações devido a vegetação exótica em interação com essas manchas. Além disso, a porção estudada deste promontório está isolada inclusive pela via expressa que conecta Itajaí a Balneário Camboriú. 
ZIEMBOWICZ, T. et al. Análise do uso e cobertura do solo dos ...

\section{Promontório da Costa Brava}

Este promontório localiza-se em Balneário Camboriú, que possui uma população de 106.220 em um território de $47 \mathrm{~km}^{2}$, sendo sua densidade demográfica de $2.310 \mathrm{hab} / \mathrm{Km}^{2}$. A base da economia é o turismo, durante a alta temporada que ocorre de dezembro à fevereiro a população chega a 1,5 milhão de habitantes. A incidência de pobreza é de $25 \%$ (IBGE, 2010).

Por meio do mapa de uso e cobertura do solo (Figura 3) pode-se verificar na tabela 3 como estão distribuídas as classificações da área de estudo.

Morraria Costa Brava - Promontório Taquaras-Taquarinhas

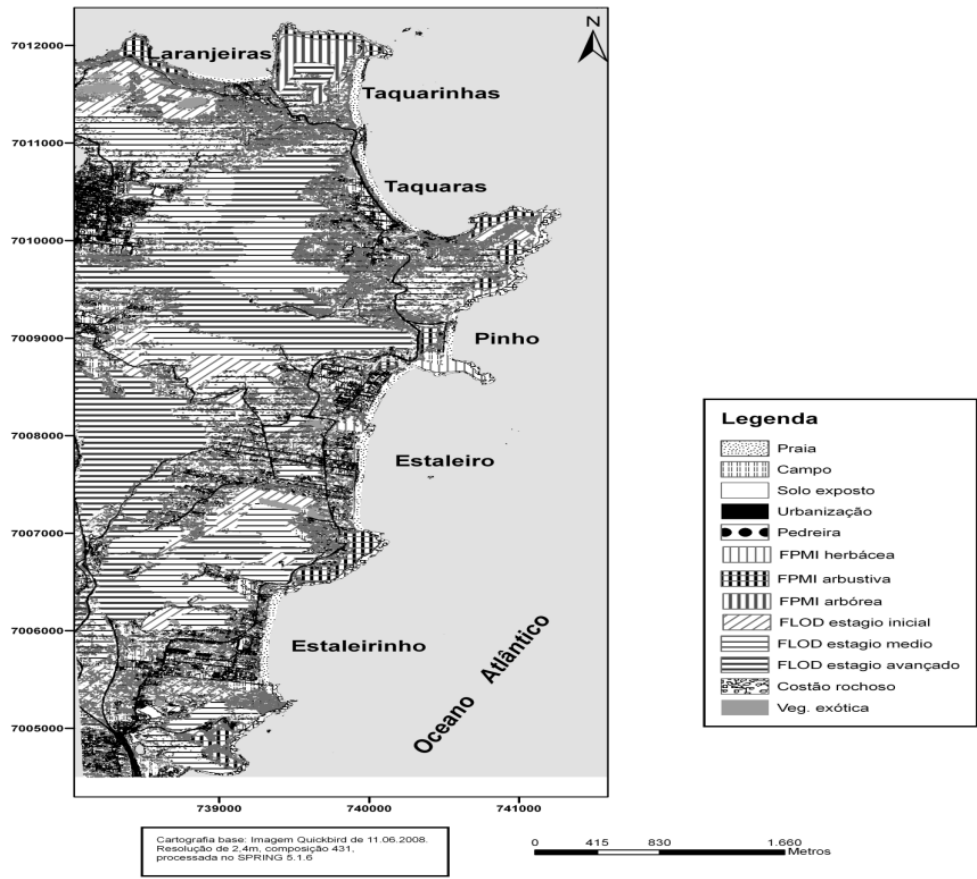

Figura 3: Mapa de uso e ocupação do solo do Promontório da Costa Brava em Balneário Camboriú - SC. 
ZIEMBOWICZ, T. et al. Análise do uso e cobertura do solo dos ...

Importante citar a rodovia Interpraias que trouxe maior pressão pela urbanização em todo este promontório, pois esta atravessa de norte a sul essa região e favorece o crescimento urbano nas suas proximidades. Possibilita a locomoção e a implementação de novas moradias. Além dessa via, existe também a presença da BR-101 que isola a área a oeste, ao norte a cidade de Balneário Camboriú com toda a sua infra-estrutura e, ao sul, a cidade de Itapema.

Por outro lado, neste promontório é evidente a presença de heterogeneidade espacial dos tipos de vegetação, corroborando para uma diversidade de habitats e refúgios para a vida silvestre (Barreto, 1999; Machado et al, 2004). No entanto, o desenvolvimento da região atual opera com maior pressão sobre os remanescentes e resulta em isolamento dos fragmentos, comprometendo a manutenção desta biodiversidade.

Tabela 3: Dados sobre as formações vegetacionais do Promontório da Costa Brava - Balneário Camboriú, SC.

\begin{tabular}{lcc}
\hline & Área (ha) & Proporção (\%) \\
\hline Praia & 26,50 & 1,08 \\
Costão Rochoso ou Costeira & 43,51 & 1,77 \\
Solo Exposto & 48,82 & 1,98 \\
Urbanização & 75,66 & 3,07 \\
Pedreira & 7,90 & 0,32 \\
Corpo d'água & 941,78 & 38,24 \\
Campo & 110,96 & 4,50 \\
Vegetação exótica & 41,96 & 1,70 \\
Mangue & 0,41 & 0,02 \\
Restinga Herbácea & 64,09 & 2,60 \\
Restinga Arbustiva & 86,19 & 3,50 \\
Restinga Arbórea & 35,58 & 1,44 \\
Estágio Inicial & 254,96 & 10,35 \\
Estágio Médio & 332,13 & 13,49 \\
Estágio Avançado & 392,11 & 15,92 \\
TOTAL & $2.462,55$ & 100 \\
\hline
\end{tabular}


ZIEMBOWICZ, T. et al. Análise do uso e cobertura do solo dos ...

Cabe destacar que fragmentos maiores permitem o estabelecimento de mais espécies devido a maior área, conforme estabelece a Teoria da Biogeografia de Ilhas (MARENZI, 2004). Da mesma forma, a conectividade possibilita o fluxo gênico e a locomoção entre as manchas de paisagem. Assim também, a heterogeneidade dos remanescentes permite que maior diversidade de espécies os habitem e haja mais nichos ecológicos. Esses três elementos (maior área, heterogeneidade e conectividade) devem preferencialmente estar atuando em conjunto para que haja uma conservação mais abrangente e duradoura (RIBEIRO et.al, 2009).

No caso desta área de estudo é percebido que as manchas de maior potencial de nichos ecológicos, FLOD em estágio avançado, encontram-se sem conectividade. É preocupante ainda, a ausência de integridade ecológica, uma vez a inexistência de amostras representativas de Floresta Clímax, onde nesta tipologia é possível encontrar maior complexidade estrutural e funcional, de acordo com (Odum \& Barret, 2007), sendo que as comunidades climácicas se encontram em estabilidade dinâmica sob o efeito de clareira.

Portanto, em um mesmo tipo de mancha é possível encontrar representantes de estágio inicial (espécies pioneiras com banco de sementes), médio e avançado (espécies secundárias com banco de plântulas), além das espécies climácicas de maior porte e interações bióticas, resultando em maior biodiversidade (MARENZI, 2004).

\section{Cenário entre os promontórios}

Apesar dos três promontórios estarem localizados na região centro-norte catarinense, é possível verificar que o uso e a cobertura ocorrem de forma diferenciada entre eles. Na tabela 4 é possível verificar a situação do cenário encontrado para os três promontórios. 
ZIEMBOWICZ, T. et al. Análise do uso e cobertura do solo dos ...

Tabela 4: Cenário geral dos Promontórios do centro-norte catarinense.

\begin{tabular}{lrrr}
\hline & $\begin{array}{c}\text { Praia } \\
\text { Vermelha }\end{array}$ & $\begin{array}{c}\text { Cabeçuda } \\
\text { S }\end{array}$ & $\begin{array}{c}\text { Costa } \\
\text { Brava }\end{array}$ \\
\hline Início da colonização & 1750 & 1820 & 1826 \\
Área Municipal (ha) & 6.200 .000 & 28.900 & 4.700 \\
Área Maciço (ha) & $1.977,61$ & 121,19 & $2.462,55$ \\
População Mun. & 25.141 & 183.373 & 106.220 \\
Hab/km & 406 & 634 & 2.310 \\
\hline
\end{tabular}

Atualmente, o município de Penha desenvolve-se por meio de três setores que são o agrícola, o pecuário, o pesqueiro e o turístico. Este último setor se torna cada vez mais exigente, onde os veranistas buscam uma infra-estrutura compatível com seus padrões de vida urbana. Todavia, percebe-se que apesar das belezas naturais atraírem turistas para Penha; são feitas novas exigências para melhorias que alteram e degradam o ecossistema (FARIAS, 2002).

A substituição de espécies nativas por exóticas, a retirada da vegetação de restinga e da Floresta Ombrófila Densa para implantação de loteamentos, a utilização de encostas para extração de material para utilização em obras, ocupação irregular da faixa litorânea, situação inadequada de despejo de lixos em áreas de mata são algumas das pressões verificadas em campo e citadas por Farias (op cit) sinalizando a modificação que vem ocorrendo sobre os recursos naturais em Penha.

O que favorece a presença da Floresta Ombrófila Densa Clímax em Penha é reforçada pela lei municipal no 1804 de 2001 (Plano Diretor), que delimita as zonas de preservação permanente exatamente pelas manchas de paisagem definidas por clímax e estágio avançado. Além disso, o plano diretor do município define como zona especial de conservação ambiental toda a Morraria da Praia Vermelha. Outro fator que contribui para a manutenção do ecossistema da área é que a ocupação humana permaneceu mais 
ZIEMBOWICZ, T. et al. Análise do uso e cobertura do solo dos ...

intensa na Armação do Itapocorói numa planície pesqueira. A permanência dessa legislação irá ser essencial para a perpetuidade do ambiente natural, porém o processo de urbanização que ocorre na porção norte e sul da Morraria pode avançar sobre a vegetação nativa comprometendo à longo prazo esse ecossistema.

Christoffoli (2003) afirma que nas décadas de 70 e 80 houve uma popularização da praia de Cabeçudas, considerando que a área possui intensa modificação do meio natural, pois não possui Floresta Ombrófila Densa em estágio avançado, assim como verificou-se a presença de vegetação exótica invasora composta por Pinus sp. e Eucalyptus sp.. Para um cenário futuro, pode ser que a área seja comprimida pelos empreendimentos imobiliários instalados em suas proximidades, principalmente na praia Brava. No entanto, o fato de existir domínio desta área pela Marinha do Brasil, tendendo permanecer desocupada em relação a residências ou outros empreendimentos.

O grande destaque da região de Balneário Camboriú impreterivelmente é o setor turístico, com a implantação dos empreendimentos turísticos para atrair a população visitante, ao mesmo tempo, que proporciona diversos lugares de lazer, reduz a qualidade do ambiente litorâneo, degradando os ecossistemas. A privatização dos espaços públicos por empreendimentos imobiliários que visam supervalorizar lotes compromete áreas de mata nativa em Balneário Camboriú e ocupam de forma intensa o litoral (CARMO, GADOTTI \& Bóia, 1999). Para estes autores, as comunidades litorâneas abandonam as práticas culturais e buscam o mercado de trabalho ligado ao turismo, comércio e serviço público, resultando numa pressão sobre os recursos naturais devido às forçantes do turismo de massa.

É possível perceber também que a densidade demográfica em Balneário Camboriú é a maior em relação aos outros dois municípios, tendo como valor $2.310 \mathrm{hab} / \mathrm{km}^{2}$ (tabela 4). Portanto, o uso e a cobertura do solo se intensificaram no promontório da Costa Brava, resultando em um processo de urbanização mais intenso, quando comparado aos outros dois promontórios, ou seja, 
ZIEMBOWICZ, T. et al. Análise do uso e cobertura do solo dos ...

a Costa Brava se caracteriza por uma ocupação de residências permanentes.

No entanto, a porcentagem de urbanização neste promontório é menor (tabela 3) decorrente do recorte das áreas de estudo, considerando que no promontório de Cabeçudas foi inserida parte da planície ocupada pelo bairro de Cabeçudas, assim como no promontório da Praia Vermelha foi incluído toda a Morraria, inserindo suas vertentes leste e oeste. Enquanto que na Costa Brava considerou-se apenas a porção leste, referente à constituição da APA da Costa Brava.

No promontório da Costa Brava as manchas de paisagem definidas como Floresta Ombrófila Densa em estágio avançado estão localizadas sobre as áreas definidas na Conama 303/02, também estão inseridas em zonas de preservação permanente e de área natural, estabelecidas pelo plano diretor do município. Contudo, verifica-se uma intensa fragmentação dessas áreas, com os seus arredores preenchidos por vegetação em estágio médio e inicial, além da inserção dos novos loteamentos.

Referente ao promontório do Farol estudou-se apenas uma ponta do maciço geológico, este encontra-se isolado e com predominância de espécies exóticas e vegetação da Floresta Ombrófila Densa em estágio inicial e médio. No entanto, especialmente decorrente de porção de área menor se comparado aos outros dois promontórios.

Devido a ausência de corredores ecológicos ligando os três promontórios e a presença de sumidouros referentes a BR-101 que margeia todo o litoral centro-norte, a Interpraias que margeia a Costa Brava, a Rodovia Oswaldo Reis que conecta Itajaí a Balneário Camboriú, a distribuição da biota na área é dificultada e compromete a dinâmica de metapopulação (MARENZI, 2004; VANDERMEER, 2010).

Quando o ambiente é modificado de uma floresta contínua para diversas manchas isoladas, as espécies podem adaptar-se as novas condições do habitat, modificando ou ampliando seu nicho ecológico. Muitas vezes, as espécies que evoluíram numa floresta 
ZIEMBOWICZ, T. et al. Análise do uso e cobertura do solo dos ...

não conseguem perpetuar e sobreviver no ecossistema perturbado, pois as suas adaptações ecológicas estão configuradas para um ambiente contínuo de vegetação (GIMENES \& ANJOS, 2003).

Espécies de aves frugívoras de dossel podem ter suas populações comprometidas pelos efeitos da fragmentação. Todavia, espécies de borda de mata podem beneficiar-se e colonizar áreas alteradas. Dessa forma, a comunidade original declina ou pode até extinguir espécies localmente, principalmente por causa das que possuem uma dieta especializada como as frugívoras e insetívoras, enquanto que as generalistas, como as onívoras aumentam a riqueza e abundância (Antunes, 2005). Considerando a espécie Turdus rufiventris que é típica de borda de mata e onívora, contribuindo para a propagação da palmeira Euterpe edulis encontrada nos três promontórios, favorecendo a perpetuidade do ecossistema.

A vegetação Clímax é caracterizada por comunidades florestais maduras que estão num equilíbrio dinâmico, fornecem habitat e diversidade de alimento para todas as espécies, para que assim as espécies da flora e da fauna se autoperpetuam indefinidamente, exceto se ocorrer pressões negativas sobre o ecossistema (ODUM \& BARRET, 2007; Wilson et al., 2010).

Porém, a fragmentação florestal de uma vegetação clímax ou dos outros estágios resulta em efeito de borda, de acordo com o perímetro da mancha, isto causa mudanças ecológicas abruptas e cria um ambiente com condições hostis para a regeneração da floresta. Ao longo do tempo, essas bordas que recebem intensa luminosidade e efeito eólico lateralmente avançam sobre o fragmento causando o estrangulamento da vegetação remanescente e levando-a ao colapso (GASCON, WILLIAMSON \& FONSECA, 2000).

O resultado desse processo é um empobrecimento da diversidade de espécies no interior da mancha de floresta devido a mortalidade maior do que o número de nascimentos (GASCON, WILLIAMSON \& FONSECA, 2000). Essa vegetação pioneira que se desenvolve na borda e também nas encostas recortadas por vias 
ZIEMBOWICZ, T. et al. Análise do uso e cobertura do solo dos ...

públicas e privadas foram visualizadas em campo, grande parte delas era colonizada por espécies exóticas.

Por fim, a vegetação Clímax foi verificada apenas no Promontório da Praia Vermelha, o que ressalta uma situação de ausência de integridade ecológica ao analisar os três promontórios em conjunto. Principalmente, pela expansão populacional e por consequência na transformação dos ambientes naturais que ocorre atualmente e poderá intensificar-se no futuro.

\section{Referências bibliográficas}

Antunes, A. Z. Alterações na composição da comunidade de aves ao longo do tempo em um fragmento florestal no sudeste do Brasil. Ararajuba, vol. 13, p. 47-61, 2005.

Bayon, R.; Jenkins, M. The business of biodiversity. Nature, vol 466, p.184-185, 2010.

Brasil, Resolução no 04 de 1994. Define a vegetação primária e secundária nos estágios inicial, médio e avançado de regeneração da Mata Atlântica.

, Resolução no 26 de 1994. Define vegetação primária e secundária nos estágios inicial, médio e avançado de regeneração da Mata Atlântica.

, Lei n⿳ 11428 de 2006. Dispõe sobre a utilização e proteção da vegetação nativa do Bioma Mata Atlântica.

Chediack, S.E. Efecto de la explotación forestal sobre la estructura, diversidady composición florística de los palmitales de la Selva Atlántica en Misiones, Argentina. Revista Biologia Tropical, vol. 56, p. 721-738, 2008. 
ZIEMBOWICZ, T. et al. Análise do uso e cobertura do solo dos ...

Christoffoli, A. R. Uma história do lazer nas praias: Cabeçudas - SC, 1910-1930. Itajaí: Univali, 2003.

Diegues, A.C. Ecologia Humana e Planejamento Costeiro.USP, São Paulo, 2001, p. 225.

Farias, V. F. de. Penha: 243 anos, natureza, história e cultura. Penha: Ed.do autor, 2002. p.302.

Gascon, C.; Williamson, G. B.; Fonseca, G. A. B. Receding Forest Edges and Vanishing Reserves. Science, vol. 288, p. 1356-1358, 2000 .

Gilbert, N. Can conservation cut poverty? Nature, vol.467, p.264$265,2010$.

Gimenes, M. R.; Anjos, L. dos. Efeitos da fragmentação florestal sobre as comunidades de aves. Acta Scientiarum, vol. 25, p. 391 402, 2003.

Guadagnin, D. L.; Laidner, C. Diagnóstico da situação e ações prioritárias para a conservação da zona costeira da região sul - Rio Grande do Sul e Santa Catarina. UNISINOS/FEPAM, 1999, p. 91.

Hanski, I. Metapopulation dynamics. Nature. v. 396, p. 41-49, 1998.

Horn, N. Os Promontórios Costeiros. Florianópolis, Manuscrito, 2010 .

IBGE. 2010. Instituto Brasileiro de Geografia e Estatística. Disponível em: http://www.ibge.gov.br (Acessado em $5 /$ novembro). 
ZIEMBOWICZ, T. et al. Análise do uso e cobertura do solo dos ...

IFES. Plano Estratégico de Marketing Turístico Integrado (Pemti): Inventário Turístico. Itajaí, 2007.

Li, X.; Mander, U. Future options in landscape ecology: development and research. The ecological society of America. v. 33, p. 31-48, 2009.

Machado, R. B.; Ramos Neto, M. B.; Pereira, P. G. P.; Caldas, E. F.; Gonçalves, D. A.; Santos, N. S.; Tabor, K.; Steininger, M. Estimativas de perda da área do Cerrado brasileiro. Relatório técnico não publicado. Conservação Internacional, Brasília, DF, 2004.

Marenzi, R. C. 2004. Ecologia da paisagem de um fragmento costeiro: subsídio à conservação da biodiversidade. Tese de Doutorado. Universidade Federal do Paraná - UFPR. p. 204.

Metzger, J. P.; Martensen, A.C.; Dixo, M.; Bernacci, L. C.; Ribeiro, M. C.; Teixeira, A. M. G.; Pardini, R. Time-lag in biological responses to landscape changes ina highly dynamic Atlantic forest region. Biological Conservation, vol. 142, p. 11661177,2009

Odum, E. P.; Barret, G.W. 5 ed. Fundamentos de Ecologia. São Paulo: Thomson Learning, 2007, p. 612.

Penha, Lei Complementar de Penha-SC, $n^{0} 2$ de 2007. Institui o plano diretor, bem como estabelece as normas de parcelamento, uso e ocupação do solo, o sistema viário, o perímetro urbano.

, Lei Municipal $n^{0} 1804$ de 2001. Institui a Política Municipal do Meio Ambiente.

Ribeiro, M. C., Metzger, J. P., Martensen, A. C., Ponzoni, F. J., Hirota, M. M. The Brazilian Atlantic Forest: How much is left, and 
ZIEMBOWICZ, T. et al. Análise do uso e cobertura do solo dos ... how is the remaining forest distributed? Implications for conservation. Biological Conservation, vol. 142, p. 1141-1153, 2009.

Santa Catarina, Resolução $n^{\circ} 261$. Institui os parâmetros básicos para análise dos estágios sucessionais de vegetação de restinga para o Estado de Santa Catarina. Santa Catarina: 1999.

Recebido em agosto de 2012 Aceito em junho de 2014 